ISSN 1112-9867

\title{
FAULT EVALUATION AND ADAPTIVE THRESHOLD DETECTION OF HELICOPTER PILOT USING BOND GRAPH METHOD
}

\author{
K. Imani ${ }^{*}$, A. B. Novinzadeh, K. N. Toosi \\ University of Technology, Tehran, Iran
}

Published online: 15 February 2017

\begin{abstract}
Hitherto, in the field of aerospace science and industry, some acceptable results from control behavior of human operator (pilot), are caught using usual methods. However, very fewer research, has been done based on personal characteristics. The performed investigations, show that many of happened faults (especially in helicopter), would result to the loss of natural behavior of system, and eventually some fatal accidents. Therefore, development of tools of assessment of pilot in this dynamical system, is one of the vital necessities. The tools of management of system, should be such that, can show the fault. The object of this paper is assessment of the modelled pilot in a simulator, in presence of standard fly inputs. For this purpose the performance of the pilot for collective and cyclic control of the helicopter, is investigated. The used methods are based on mathematical models and by bond graph modeling method. The existence of uncertainties in the simulator system and the modeled pilot's behavior, causes creation of fault threshold, for human behavior of pilot. By having these fault thresholds, the improper actions of the pilot, cause creation of behavioral reminders, which can perform the assessment of the pilot. By other speech, using fault detection and isolation (FDI), by bond graph method in state space, the assessment is performed and a non-zero reminder shows existence of fault in the system.
\end{abstract}

Author Correspondence, e-mail: author@gmail.com

doi: http://dx.doi.org/10.4314/jfas.v9i1s.696 
Therefore, in this paper there is the novelties for modeling the pilot's body performance and the helicopter's systems integrally and designing a fault detection system for it that shows the source of the fault, and obviously it can be useful in aviation industry.

Keywords: Helicopter Control, Fault Detection and Isolation, Human Fault, Bond Graph.

\section{INTRODUCTION}

In the investigations of various boards of assessment of human faults in aviation accidents occurrence, including International Transport Safety Board, it is seen that the most major reasons and factors of accidents occurrence, are human faults (about $88 \%$ to 91\%). Also, in many of them human faults beside other reasons, cause the accident. It should be noticed that, in human faults, it is not only the pilot that is responsible of it, but other people that are working in the aviation industry are included too. However, the pilot is the most major source of the human faults, such that it is included in $81 \%$ of human faults.

A lot of definitions and interpretations from the human faults have been done, and various models of it has been presented and investigated the reasons of accident occurrence in the case of chain theory, from Heinrichin $1931^{[1]}$, to Industrial Safety Rules of Reason's Swiss Cheese in $1990^{[2]}$.In 2000 a comprehensive and overall term was presented by Wiegman and Shappell ${ }^{[3]}$, that is consist of all of the work conditions and stages of physical and mental activities. In 1991 an useful map for human faults was suggested by Sender and Moray ${ }^{[4]}$, that has four classifications:

Prospective emerge classification (neglect, Switch action substitution and ...).

Internal process classification (one route motion control fault, additional task density and decision fault).

Neurological psychological mechanism classification (amnesia, stress and mental pressure, notice).

External process classification (incorrect and weak designing of tools).

In 1993, it was said by McCormik and Sanders ${ }^{[5]}$, that human fault is a human improper or unexpected decision or behavior that reduces effectiveness, safety and action of the system, or has the potential of its reduction. Of course, this fault can consist of other people than the pilot, such as the manager, designers of the system, repairing and maintenance engineers and others. It 
was alleged by Petersen in $1996^{[6]}$ that in the back of each accident, human fault is hidden as the main reason.

For investigation of human fault, some models for human operator have been presented. Arnold Tustin was the pioneer of modeling of human operator. In the mid-1940s, he was studying on the artillery turret, and in 1947 published a paper by the name of "The nature of human operator response in manual control and its concepts for control designing" "7]. It was supposed by Tustin that human can be showed by a linear and constant differential equation coefficient. At that time, linear servomechanisms theory was well developed and could be used in manual control tasks analysis. In 1969 a viewpoint for human operator modeling was presented by McRuer ${ }^{[8]}$, which is returned to crossover models. The nature of this model is its consistency by machine dynamics, and the effect that is calculated for nonlinearity in human-machine system, was presented by it. An optimal control model (OCM) was developed in $1970^{[9]}$, which well shows the behavior of human operator by a nearly optimal method, considering its personal limitations, constraints and lack of control. A model was presented in 1985by Ronald Hess that tried to mimic psychomotor structure of human ${ }^{[10]}$. Recently, some studies for optimization and development of Hess's model has been done by Cardallo that its nature consist of force and motion responses in the model ${ }^{[11]}$.

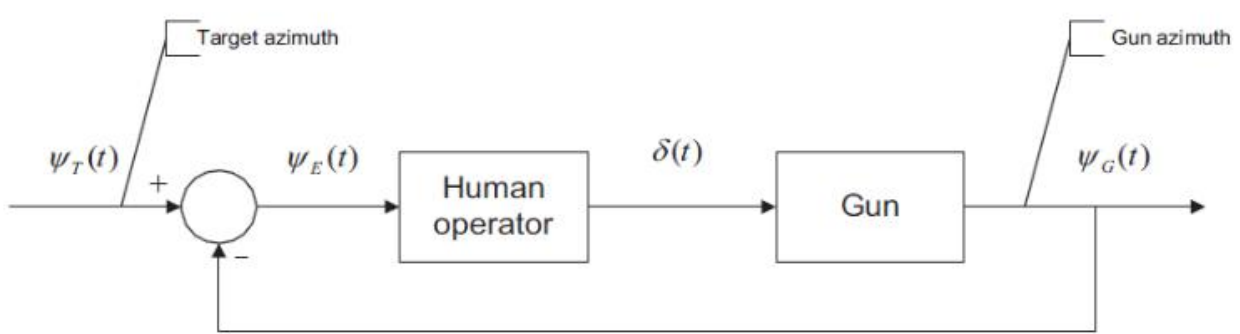

Fig.1. The block diagram of the control system of artillery turret ${ }^{[7]}$

The methods of model-based Fault Detection an Isolation as a research field have been used very much in the control systems. These methods are based on consistency tests, which in them the measurements from the physical system are compared to the available information in the model. The resulted differences are called remainders, which are sensitive to the existence of fault in the system. A reminder that is non-zero shows non-consistency or unusual deviation of an estimated parameter in the system. However, the modelling misses and perturbations in the complicated engineering system are unavoidable, so the reminders even in the case that no fault has been 
occurred, don't become exactly zero, always. Therefore, it is necessary that fault detection algorithms, be robust against the noise and uncertainty of the parameters.

For considering uncertainty of parameters a detailed model of the system is required, that uncertainty of parameters be considered in it. For simulation of each mechanism, firstly the equations that are ruled over it should be extracted, and then these equations should be solved by a proper method. Some of the available methods for extracting the equations are NewtonLagrange method, block diagram, flow diagram, linear graph of the system and bond graph method. Between of them bond graph is one of the most powerful methods for simulation of dynamical systems. Its advantages are that: first, all of the equations are integrally, so the number of equations will be not more than state equations, and more important that, systems in various energy domains including electrical, mechanical, chemical, hydraulic, pneumatics and ..., can be modeled by it. Furthermore, there is no need to suppose the system, linear. This method was used for modeling dynamical systems firstly, in $1961^{[12]}$. Later, in 1999 it was used for observability and controllability, using its structural characteristics, by Dauphin-Tanguy ${ }^{[13]}$. After that, in 2001, bond graph was developed for fault detection and isolation using causality analysis method ${ }^{[14]}$. Although, quantity analysis by bond graph method for simple systems for the first time in 1995, was used for retaining the reminder ${ }^{[15]}$, but this method was developed by Ould-Bouamama in $2003^{[16]}$.

In this paper it is tried to model collective and cyclic control system of the helicopter including the pilot's hand that moves the handle. Then the bond graph FDI method is used for obtaining reminders.

\section{Collective and Cyclic Control System of Helicopter}

Collective and cyclic control system are two systems of helicopter, which the first one defines the step angle of the main rotor and the second one defines the angle of the plate that the main rotor is rotating in it ${ }^{[17]}$. The overall schematic of both systems can be seen in figure 2 .

Collective control system is manipulated by an one-degree freedom handle than can be moved by the pilot's hand. The force from the handle throughsome rods is transmitted to a ball bearing that is installed under the rotor. The transmission rods system is consist of some parts that may move directly or rotate to transfer the movement to the ball bearing. At the end of it, there is four beams that move parallel and synchronic to each other to up and down that make the ball bearing, to go 
to up or down. The ball bearing is connected to the attack side of the blades of the rotor, so this movement changes the angle of the blades.

In cyclic system a two-degree freedom handle is used that the pilot can move it in longitudinaland latitudinal directions. Like the collective control system, the movement is transferred to the ball earing by a transmission rods, but this time the beams under the ball bearing don't move synchronically, that makes the angle of the its plate be changed, and this angle is applied to the rotor's plate too.

It should be noticed that because the human force of the pilot is not enough to move the heavy rotor, a secondary hydraulic system is used to help the pilot to move the handles.

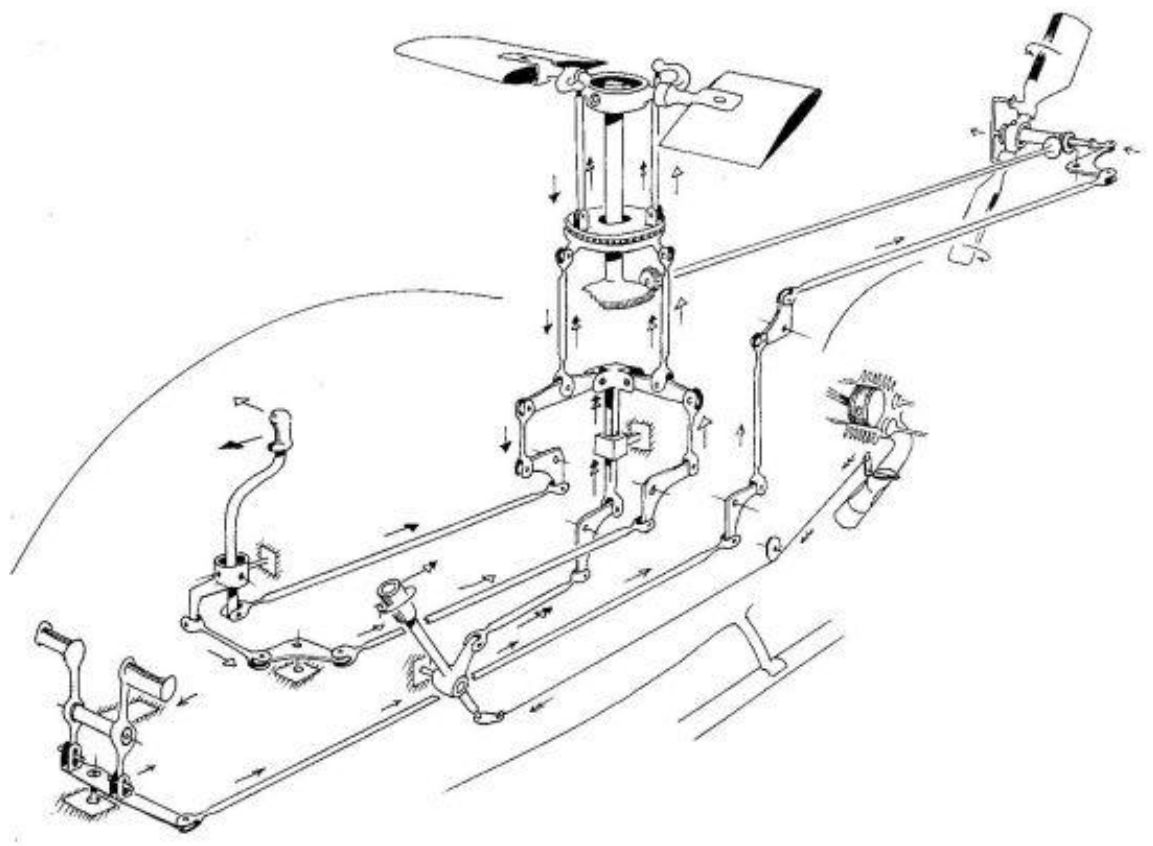

Fig.2. Schematic of collective and cyclic control system of helicopter

Designing the FDI Bond Graph of the System

In this section it is tried to bond graph model of the objected system of this paper, be established. This model is consist of the muscles of arm and forearm of the pilots, which move forearm and wrist of the hand respectively. In this paper the muscles are supposed as springs that move the bones. For the secondary hydraulic system a bi-directional jack with a standard $5 / 3$ valve is used, that its bond graph model may be found in [18].The designed bond graph model of the collective and cyclic systems may be seen in figures 3 and 4 respectively. As it can be seen, there is only few differences between them. It should be noticed that, in cyclic system, because movement is 
in both longitudinal and latitudinal directions, each of them is described by a bond graph model, but both of them is the same, only the parameters values will be different.

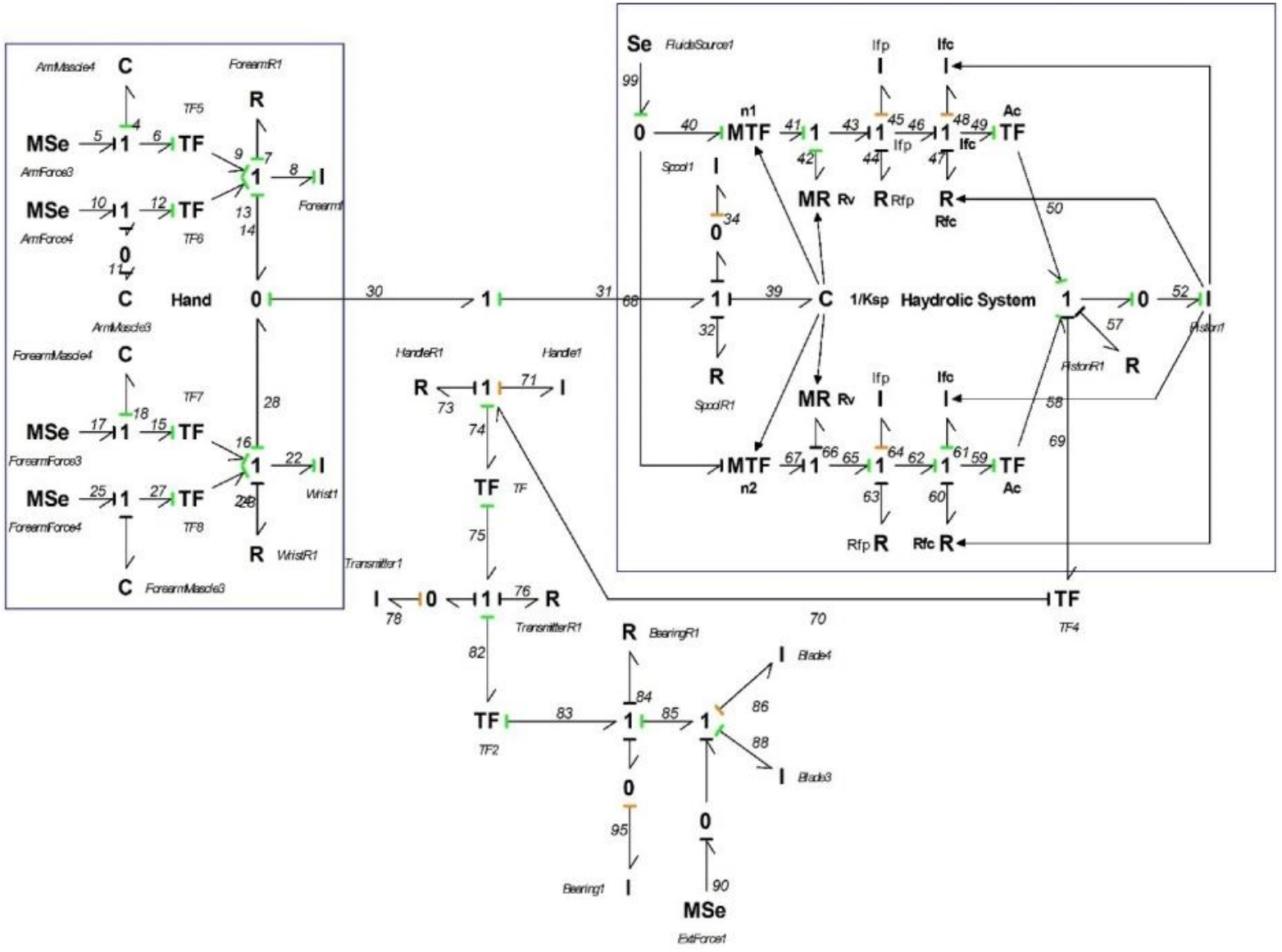

Fig.3. Bond graph model of collective control system of helicopter 


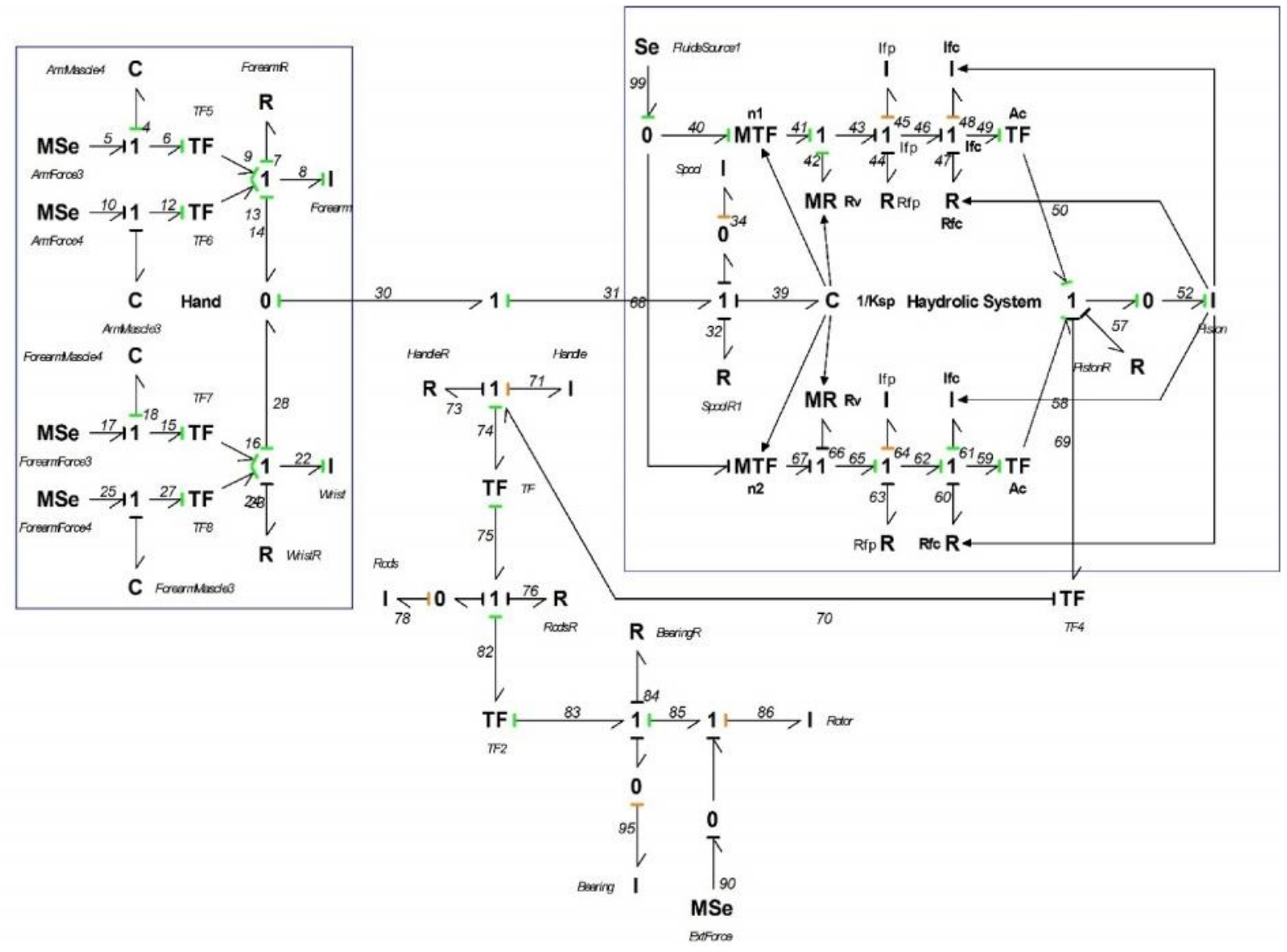

Fig.4. Bond graph model of cyclic control system of helicopter

In the next step sensors will be added to the models. In this task 9 sensors is used, in each bond graph model. It should be noticed that, when bond graph is used for extracting state equations, the measured values from the sensors, act as output from the system, while bond graph is used for fault detection, they act as input to the system, so the causalities will be different. In the used method for modeling sensors ${ }^{[14]}$, [19], beside the real sensor a virtual sensor is used also, that calculates the reminder value. In the ideal state this value should be equal to zero, but in reality, an accepted range for it should be defined. A reminder value that is outside of its secure range, shows existence of fault in the system. The bond graph model of both mentioned system with sensors may be seen in figures 5 and 6 . In this models virtual sensors are specified by $*$ sign. 


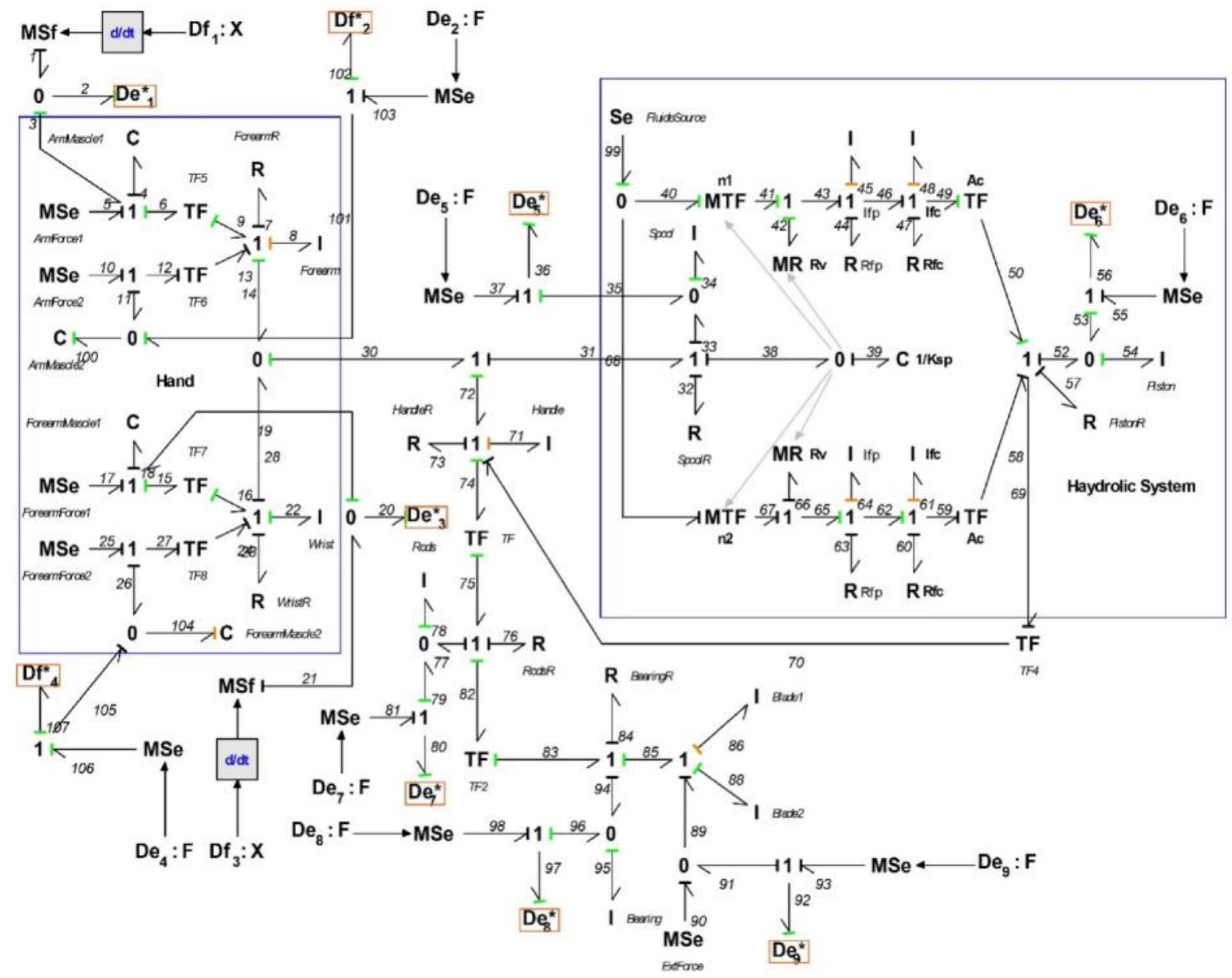

Fig.5. Bond graph model of the collective control of the system with sensors 


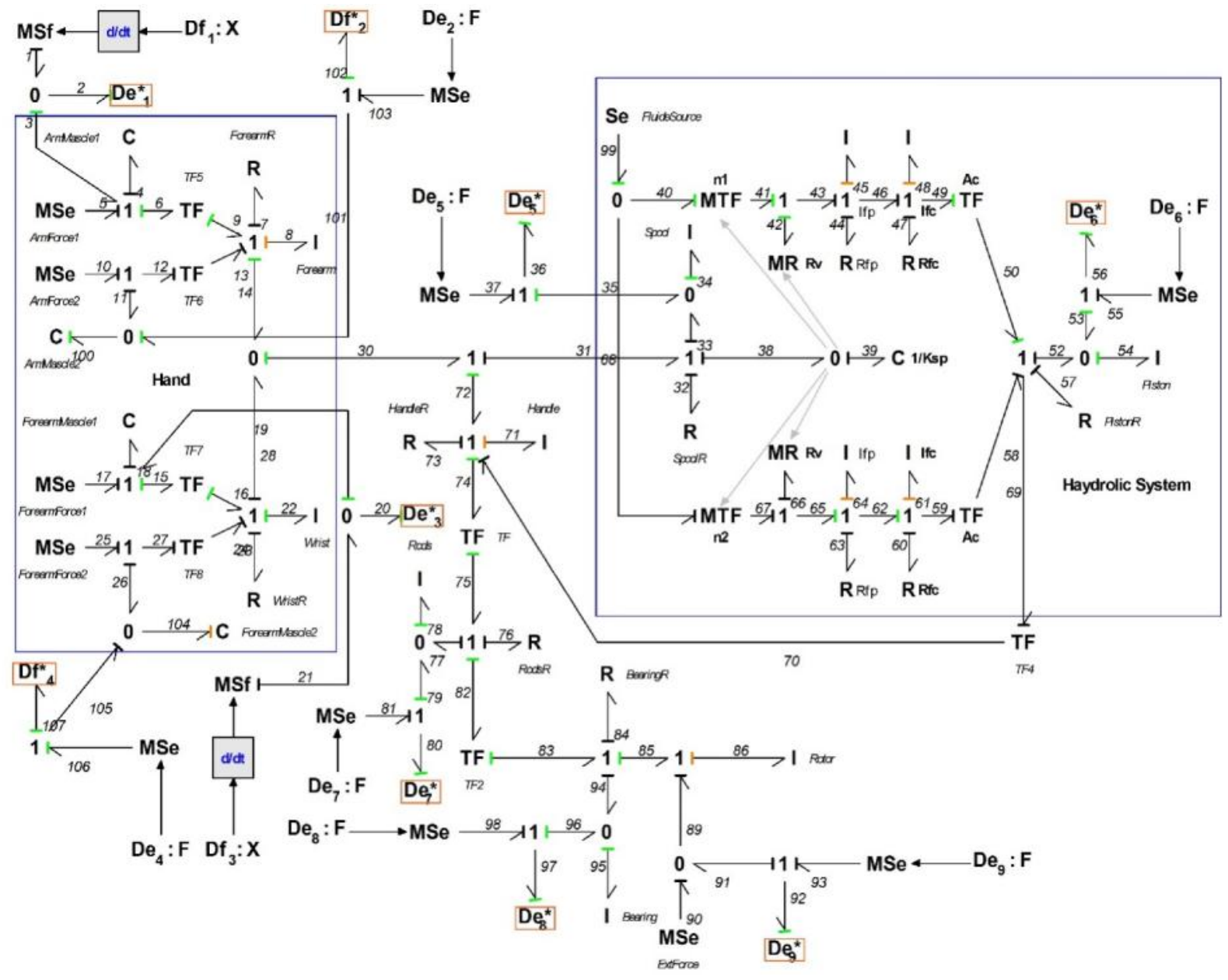

Fig.6. Bond graph model of cyclic control system of helicopter with sensors

\section{Uncertainty Bond Graph Model}

The study and analysis of robust control, for confidence from well performance of the control system against uncertainties, is the topic of many of today's researches. The analysis of robust control is performed for the purpose of designing controlling rules, such that with changing of the system's parameters in a specified range, the stability of the system be satisfied. Two models are used for studying, the stability of linear systems. The first one is recognized as canonical form, and the second one that is used in this paper, is recognized as standard interconnection model or internal feedback loop (LFT) ${ }^{[20]}$. In this form the uncertainties are isolated from the nominal parameters of the model, and their effects, are entered to the model as a feedback (Figure 7).The state equations in this form are as equation 1: 


$$
\left\{\begin{array}{c}
\dot{x}=A_{n} x+B_{n} \omega+B_{2 n} \\
z=C_{n} x+D_{11} \omega+D_{12} u \\
z=C_{2 n} x+D_{21} \omega+D_{22 n} u \\
\omega=\Delta . z
\end{array}\right.
$$

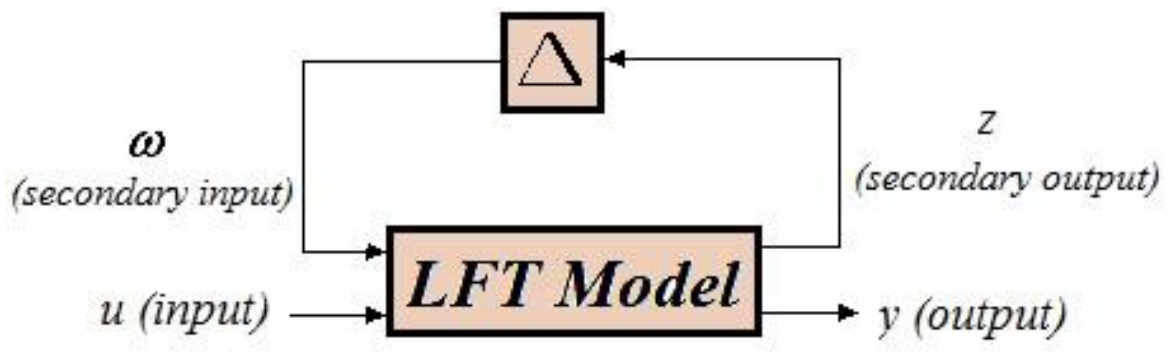

Fig.7. LFT stability form

In this equation $B_{2 n}=B_{n}, C_{2 n}=C_{n}, D_{22 n}=D_{n}$ and $\omega$ and $z$ are secondary input and output of the system, respectively, and $\Delta$ is a diagonal matrix, that is consist of rational uncertainty of parameters.

The uncertainty of parameter $\theta$ can be shown as $\theta=\theta_{n}-\Delta \theta$. If the showing of uncertainty is desired, it is better that parameters be shown as multiplex of nominal parameter and the uncertainty term:

$\theta=\theta_{n}-\Delta \theta=\theta_{n}\left(1+\frac{\Delta \theta}{\theta_{n}}\right)=\theta_{n}\left(1+\delta_{\theta}\right), \quad \delta_{\theta}=\frac{\Delta \theta}{\theta_{n}}$

If in the ruled relation overthe element, the parameter be shown in the case $1^{\prime} \theta$, the uncertainty of the parameter in the LFT form can be shown as below:

$\frac{1}{\theta}=\frac{1}{\theta_{n}+\Delta \theta}=\frac{\theta_{n}}{\theta_{n}\left(\theta_{n}+\Delta \theta\right)}=\frac{\left(\theta_{n}+\Delta \theta\right)-\Delta \theta}{\theta_{n}\left(\theta_{n}+\Delta \theta\right)}=\frac{1}{\theta_{n}}\left(1-\frac{\Delta \theta}{\theta_{n}+\Delta \theta}\right)=\frac{1}{\theta_{n}}\left(1+\delta_{1 / \theta}\right), \delta_{1 / \theta}=-\frac{\Delta \theta}{\theta_{n}+\Delta \theta}$

In bond graph modeling, for showing the parameters in the standard form, when parameters have uncertainty, modulated sources are used ${ }^{[21],[22],[23]}$.

The bond graph models of the systems that are the topic of this paper, in the case that LFT model for uncertainty, is added to them, are shown in figures 8 and 9 . 


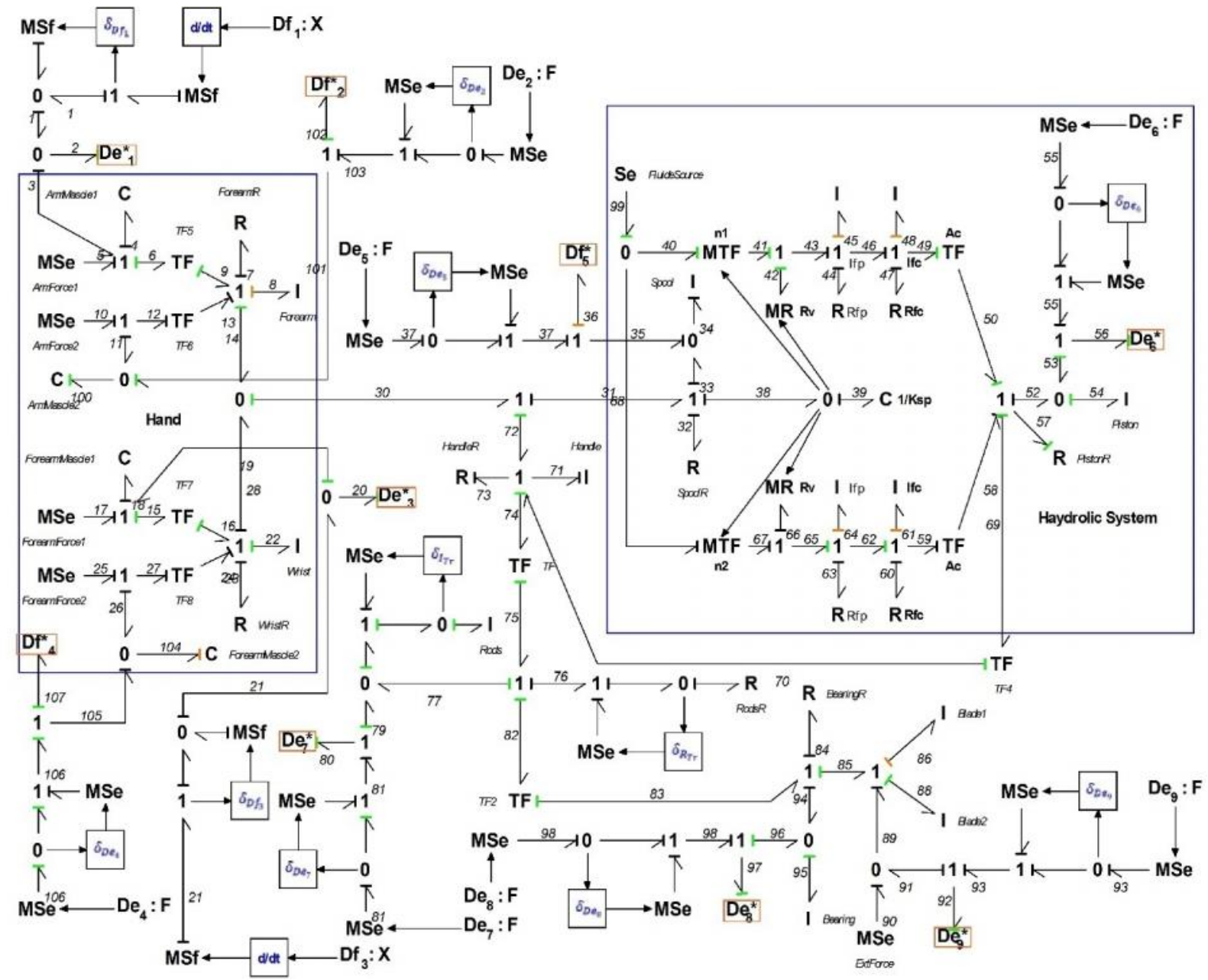

Fig.8. Bond graph model of the collective control of the system with LFT model 


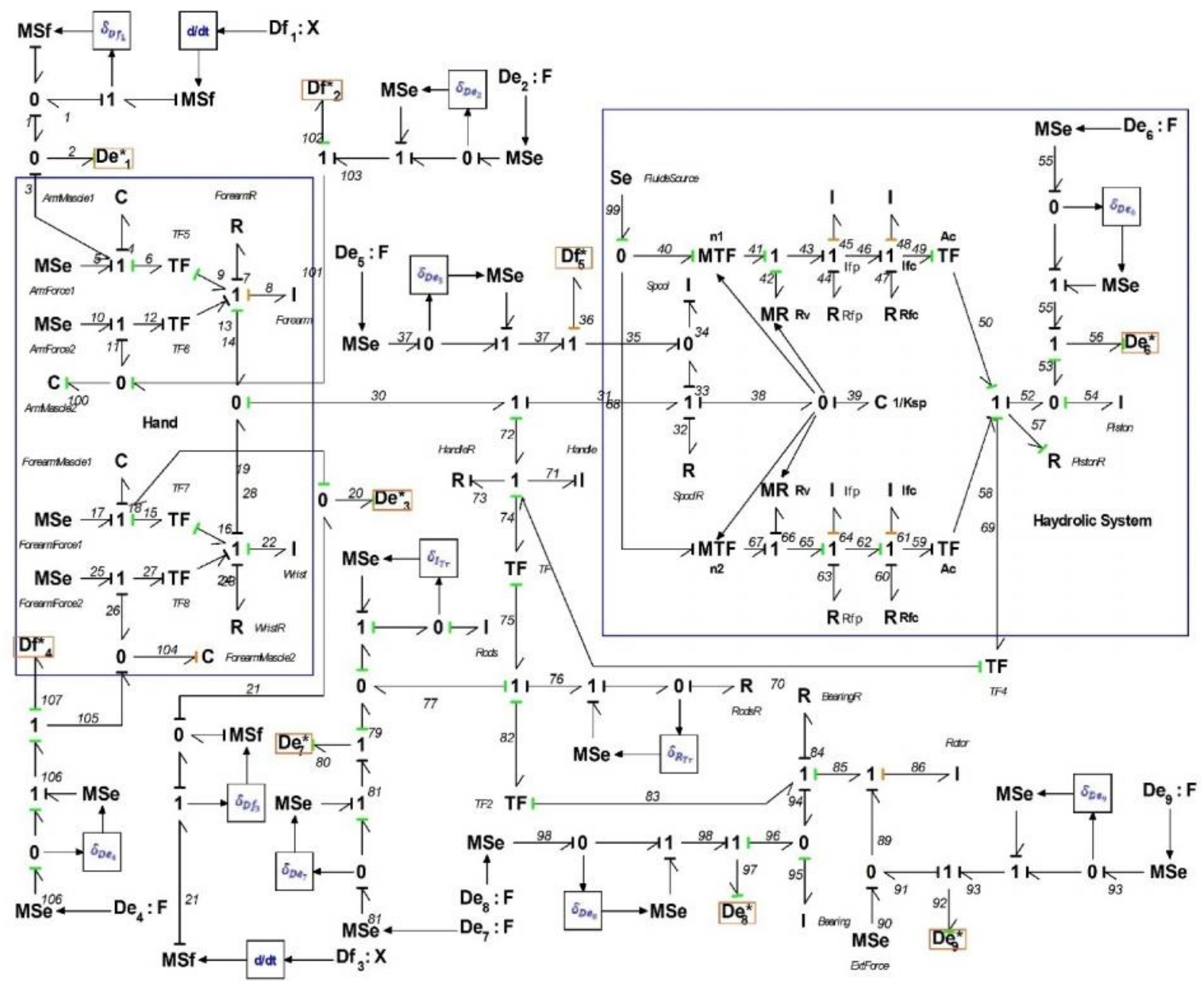

Fig.9. Bond graph model of the cyclic control of the system with LFT model

The state equations are extracted as below:

$A R R_{1}=\frac{D f_{1}}{C_{A r m_{1}}}+T f_{5}\left(R_{\text {Forearm }} T f_{5} \dot{D} f_{1}+l_{\text {Forearm }} T f_{5} \ddot{D} f_{1}+R_{S p o o l}\left(T f_{5} \dot{D} f_{1}+T f_{7} \dot{D} f_{3}\right)+\right.$ $\left.\frac{T f_{5} D f_{1}+T f_{7} D f_{3}}{C_{\text {Spring }}}+D e_{5}-T f_{6}\left(M s e_{A r m_{2}}-D e_{2}\right)\right)-M s e_{A r m_{1}} \pm \omega_{1} \pm \omega_{2} \pm \omega_{3} \pm \omega_{4} \pm \omega_{5} \pm \omega_{6} \pm$ $\omega_{7} \pm \omega_{8} \pm \omega_{9}$ 


$$
\begin{aligned}
& \left\{\begin{array}{c}
\omega_{1}=\delta_{D f_{1}} \frac{D f_{1}}{C_{A r m_{1}}} \\
\omega_{2}=\delta_{D f_{1}} \dot{D} f_{1} T f_{5}^{2} R_{\text {Forearm }} \\
\omega_{3}=\delta_{D f_{1}} \dot{D} f_{1} T f_{5}^{2} I_{\text {Forearm }} \\
\omega_{4}=\delta_{D f_{1}} \dot{D} f_{1} T f_{5}^{2} R_{\text {Spool }} \\
\omega_{5}=\delta_{D f_{3}} \dot{D} f_{3} T f_{5} T f_{7} R_{\text {Spool }} \\
\omega_{6}=\delta_{D f_{1}} \frac{D f_{1} T f_{5}^{2}}{C_{\text {Spring }}}
\end{array}\right. \\
& \omega_{7}=\delta_{D f_{3}} \frac{D f_{3} T f_{5} T f_{7}}{C_{\text {spring }}} \\
& \omega_{8}=\delta_{D e_{5}} D e_{5} T f_{5} \\
& \omega_{9}=\delta_{D e_{2}} D e_{2} T f_{5} T f_{6}
\end{aligned}
$$

$A R R_{2}=C_{A r m_{2}} \dot{D} e_{2}-T f_{5} T f_{6} \dot{D} f_{1} \pm \omega_{1} \pm \omega_{2}$

$\left\{\begin{array}{l}\omega_{1}=\delta_{D e_{2}} \dot{D} e_{2} C_{A r m_{2}} \\ \omega_{2}=\delta_{D f_{1}} \dot{D} f_{1} T f_{5} T f_{6}\end{array}\right.$

$A R R_{3}=\frac{D f_{3}}{C_{\text {Forearm }}}+T f_{7}\left(R_{\text {Wrist }} T f_{7} \dot{D} f_{3}+I_{\text {Wrist }} T f_{7} \ddot{D} f_{3}+R_{\text {Spool }}\left(T f_{5} \dot{D} f_{1}+T f_{7} \dot{D} f_{3}\right)+\right.$

$\frac{T f_{5} D f_{1}+T f_{7} D f_{3}}{c_{\text {Spring }}}+D e_{5}-T f_{8}\left(\right.$ Mse $\left.\left._{\text {Forearm }_{2}}-D e_{4}\right)\right)-$ Mse $_{\text {Forearm }_{1}} \pm \omega_{1} \pm \omega_{2} \pm \omega_{3} \pm \omega_{4} \pm$ $\omega_{5} \pm \omega_{6} \pm \omega_{7} \pm \omega_{8} \pm \omega_{9}$

$$
\left\{\begin{array}{c}
\omega_{1}=\delta_{D f_{3}} \frac{D f_{3}}{C_{\text {Wrist }}} \\
\omega_{2}=\delta_{D f_{3}} \dot{D} f_{3} T f_{7}^{2} R_{\text {Wrist }} \\
\omega_{3}=\delta_{D f_{3}} \ddot{D} f_{3} T f_{7}^{2} I_{\text {Wrist }} \\
\omega_{4}=\delta_{D f_{3}} \dot{D} f_{3} T f_{7}^{2} R_{\text {Spool }} \\
\omega_{5}=\delta_{D f_{1}} \dot{D} f_{1} T f_{5} T f_{7} R_{\text {Spool }} \\
\omega_{6}=\delta_{D f_{3}} \frac{D f_{1} T f_{7}^{2}}{C_{\text {Spring }}} \\
\omega_{7}=\delta_{D f_{1}} \frac{D f_{1} T f_{5} T f_{7}}{C_{\text {Spring }}} \\
\omega_{8}=\delta_{D e_{5}} D e_{5} T f_{7} \\
\omega_{9}=\delta_{D e_{4}} D e_{4} T f_{7} T f_{8}
\end{array}\right.
$$


$A R R_{4}=C_{\text {Wrist }_{2}} \dot{D} e_{4}-T f_{7} T f_{8} \dot{D} f_{3} \pm \omega_{1} \pm \omega_{2}$

$\left\{\begin{array}{l}\omega_{1}=\delta_{D e_{4}} \dot{D} e_{4} C_{\text {Wrist }_{2}} \\ \omega_{2}=\delta_{D f_{3}} \dot{D} f_{3} T f_{7} T f_{8}\end{array}\right.$

$A R R_{5}=D e_{5}-\frac{1}{T f_{5}}\left(M s e_{A r m_{1}}-\frac{D f_{1}}{C_{A r m_{1}}}\right)-T f_{6}\left(M s e_{\text {Arm }_{2}}-\frac{T f_{5} T f_{6} D f_{1}}{C_{A r m_{2}}}\right)+T f_{5} R_{\text {Forearm }} \dot{D f_{1}}+$

$T f_{5} I_{\text {Forearm }} \ddot{D} f_{1}+\frac{T f_{5} D f_{1}+T f_{7} D f_{3}}{C_{\text {Spring }}}+R_{\text {Spool }}\left(T f_{5} \dot{D} f_{1}+T f_{7} \dot{D} f_{3}\right) \pm \omega_{1} \pm \omega_{2} \pm \omega_{3} \pm \omega_{4} \pm \omega_{5} \pm$

$\omega_{6}=\omega_{7} \pm \omega_{8} \pm \omega_{9}$

$$
\left\{\begin{array}{c}
\omega_{1}=\delta_{D e_{5}} D e_{5} \\
\omega_{2}=\delta_{D f_{1}} \frac{D f_{1}}{T f_{5} C_{A r m_{1}}} \\
\omega_{3}=\delta_{D f_{1}} \frac{T f_{5} T f_{6}^{2} D f_{1}}{C_{\text {Arm }}} \\
\omega_{4}=\delta_{D f_{1}} \dot{D} f_{1} T f_{5} R_{\text {Forearm }} \\
\omega_{5}=\delta_{D f_{1}} T f_{5} \ddot{D} f_{1} I_{\text {Forearm }} \\
\omega_{6}=\delta_{D f_{1}} \frac{T f_{5} D f_{1}}{C_{\text {Spring }}} \\
\omega_{7}=\delta_{D f_{3}} \frac{T f_{7} D f_{3}}{C_{\text {Spring }}} \\
\omega_{8}=\delta_{D f_{1}} \dot{D f_{1} T f_{5} R_{\text {Spool }}} \\
\omega_{9}=\delta_{D f_{3}} \dot{D} f_{3} T f_{7} R_{\text {Spool }}
\end{array}\right.
$$

$A R R_{6}=$

$D e_{6}-A_{\text {Cylinder }}\left(n_{1} S_{e_{\text {Fluide-Source }}}-\frac{A_{C y \text { linder }}\left(R_{V_{1}}+R_{\text {fluide-pipe }-1}+R_{\text {fluide-cylinder }-1}\right) \int D e_{6}}{I_{\text {Piston }}}-\right.$ $\left.\frac{A_{\text {Cylinder }}\left(I_{\text {fluide-pipe- } 1}+I_{\text {fluide-cylinder }-1}\right) D \epsilon_{6}}{I_{\text {Piston }}}\right)-$

$A_{\text {Cylinder }}\left(n_{2}\right.$ Se $e_{\text {Fluide-Source }}-\frac{A_{\text {Cylinder }}\left(R_{V_{2}}+R_{\text {fluide-pipe-2 }}+R_{\text {fluide-cylinder-2 }}\right) \int D e_{6}}{I_{\text {Piston }}}-$

$\left.\frac{A_{\text {Cylinder }}\left(I_{\text {fluide-pipe-2 }}+I_{\text {fluide-cylinder-2 }}\right) D e_{6}}{I_{\text {Piston }}}\right)+\frac{R_{\text {Piston }} \int D e_{6}}{I_{\text {Piston }}}+T f_{4}\left(T f\left(\frac{T f T f_{4} R_{R o d s} \int D e_{6}}{I_{\text {Piston }}}+\right.\right.$

$\frac{T f T f_{4} I_{\text {Rods }} \text { De }_{6}}{I_{\text {Piston }}}+T f_{2}\left(\frac{T f T f_{2} T f_{4} R_{\text {Bearing }} \int D e_{6}}{I_{\text {Piston }}}+\frac{T f T f_{2} T f_{4}\left(I_{\text {Bearing }}+I_{\text {Blade }_{1}}+I_{\text {Blade }_{2}}\right) D e_{6}}{I_{\text {Piston }}}-\right.$ Mse $\left.\left._{\text {Eternal }}\right)\right)-$ 
$\left.\frac{T f_{4} R_{\text {Handle }} \int D e_{6}}{I_{\text {Piston }}}-\frac{T f_{4} I_{\text {Handle }} D e_{6}}{I_{\text {Piston }}}\right) \pm \omega_{1} \pm \omega_{2} \pm \omega_{3} \pm \omega_{4} \pm \omega_{5} \pm \omega_{6} \pm \omega_{7} \pm \omega_{8} \pm \omega_{9} \pm \omega_{10} \pm$ $\omega_{11} \pm \omega_{12}$

$$
\begin{aligned}
& \omega_{1}=\delta_{D e_{6}} \int D e_{6} \\
& \omega_{2}=\delta_{D e_{6}} \frac{A_{\text {Cylinder }}^{2}\left(R_{V_{1}}+R_{\text {fluide-pipe-1 }}+R_{\text {fluide-cylinder }-1}\right) \int D e_{6}}{I_{\text {Piston }}}
\end{aligned}
$$

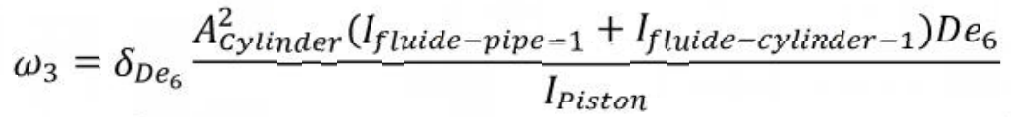

$$
\begin{aligned}
& \omega_{4}=\delta_{D c_{6}} \frac{A_{C y l i n d e r}^{2}\left(R_{V_{2}}+R_{\text {fluide-pipe-2 }}+R_{\text {fluide-cylinder-2 }}\right) \int D e_{6}}{I_{\text {Piston }}} \\
& \omega_{5}=\delta_{D e_{6}} \frac{A_{\text {Cylinder }}^{2}\left(I_{\text {fluide-pipe-2 }}+I_{\text {fluide-cylinder-2 }}\right) D e_{6}}{I_{\text {Piston }}} \\
& \omega_{6}=\delta_{\text {De }} \frac{R_{\text {Piston }} \int D e_{6}}{I_{\text {Piston }}} \\
& \omega_{7}=\delta_{D e_{6}} \frac{T f^{2} T f_{4}^{2} R_{\text {Rods }} \int D e_{6}}{I_{\text {Piston }}} \\
& \omega_{8}=\delta_{D e_{6}} \frac{T f^{2} T f_{4}^{2} I_{\text {Rods }} D e_{6}}{I_{\text {Piston }}} \\
& \omega_{9}=\delta_{\text {De }_{6}} \frac{T f^{2} T f_{2}^{2} T f_{4}^{2} R_{\text {Bearing }} \int D e_{6}}{I_{\text {Piston }}} \\
& \omega_{10}=\delta_{D e_{6}} \frac{T f^{2} T f_{2}^{2} T f_{4}^{2}\left(I_{\text {Bearing }}+I_{\text {Blade }_{1}}+I_{\text {Blade }_{2}}\right) D e_{6}}{I_{\text {Piston }}} \\
& \omega_{11}=\delta_{\text {De }} \frac{T f_{4}^{2} R_{\text {Handle }} \int D e_{6}}{I_{\text {Piston }}} \\
& \omega_{12}=\delta_{D e_{6}} \frac{T f_{4}^{2} I_{\text {Handle }} D e_{6}}{I_{\text {Piston }}}
\end{aligned}
$$


$\left.\frac{T f_{4} I_{\text {Handle }} D e_{6}}{I_{\text {Piston }}}\right)+\frac{T f T f_{4} R_{\text {Rods }} \int D e_{6}}{I_{\text {Piston }}}+T f_{2}\left(\frac{T f T f_{2} T f_{4} R_{\text {Bearing }} \int D e_{6}}{I_{\text {Piston }}}+\right.$ $\left.\left.\frac{T f T f_{2} T f_{4}\left(I_{\text {Bearing }}+I_{\text {Blade }}+I_{\text {Blade }}\right) D e_{6}}{I_{\text {Piston }}}-M s e_{\text {Eternal }}\right)\right) \pm \omega_{1} \pm \omega_{2} \pm \omega_{3} \pm \omega_{4} \pm \omega_{5} \pm \omega_{6} \pm \omega_{7} \pm$ $\omega_{8} \pm \omega_{9} \pm \omega_{10} \pm \omega_{11} \pm \omega_{12}$

$$
\begin{aligned}
& \omega_{1}=\delta_{D e_{7}} \int D e_{7} \\
& \omega_{2}=\delta_{D e_{6}} \frac{A_{\text {Cylinder }}^{2}\left(R_{V_{1}}+R_{\text {fluide }- \text { pipe }-1}+R_{\text {fluide-cylinder }-1}\right) \int D e_{6}}{T f T f_{4} I_{\text {Piston }}} \\
& \omega_{3}=\delta_{D e_{6}} \frac{A_{\text {Cylinder }}^{2}}{\left(I_{\text {fluide-pipe-1 }}+I_{\text {fluide-cylinder-1 }}\right) D e_{6}} \\
& \omega_{4}=\delta_{D e_{6}} \frac{A_{C y l i n d e r}^{2}\left(R_{V_{2}}+R_{\text {fluide-pipe }-2}+R_{\text {fluide-cylinder-2 }}\right) \int D e_{6}}{T f T f_{4} I_{\text {Piston }}} \\
& \omega_{5}=\delta_{D e_{6}} \frac{A_{\text {Cylinder }}^{2}\left(I_{\text {fluide-pipe-2 }}+I_{\text {fluide-cylinder }-2}\right) D e_{6}}{T f T f_{4} I_{\text {Piston }}} \\
& \omega_{6}=\delta_{D e_{6}} \frac{D e_{6}}{T f T f_{4}} \\
& \omega_{7}=\delta_{D e_{6}} \frac{R_{\text {Piston }} \int D e_{6}}{T f T f_{4} I_{\text {Piston }}} \\
& \omega_{8}=\delta_{D e_{6}} \frac{T f T f_{4} R_{\text {Rods }} \int D e_{6}}{I_{\text {Piston }}} \\
& \omega_{9}=\delta_{D e_{6}} \frac{T f T f_{2}^{2} T f_{4} R_{\text {Bearing }} \int D e_{6}}{I_{\text {Piston }}} \\
& \omega_{10}=\delta_{D e_{6}} \frac{T f T f_{2}^{2} T f_{4}\left(I_{\text {Bearing }}+I_{\text {Blade }_{1}}+I_{\text {Blade }_{2}}\right) D e_{5}}{I_{\text {Piston }}} \\
& \omega_{11}=\delta_{D e_{6}} \frac{T f_{4} R_{\text {Handle }} \int D e_{6}}{\text { TfI } I_{\text {Piston }}} \\
& \omega_{12}=\delta_{D e_{6}} \frac{T f_{4} I_{\text {Handle }} D e_{6}}{T f I_{\text {Piston }}} \\
& A R R_{8}= \\
& D e_{8} \\
& \frac{1}{T f_{2}}\left(\frac { 1 } { T f } \left(\frac { 1 } { T f _ { 4 } } \left(A _ { \text { Cylinder } } \left(n_{1} \text { Se } e_{\text {Fluide-Source }}-\frac{A_{\text {Cylinder }}\left(R_{V_{1}}+R_{\text {fluide-pipe-1 }}+R_{\text {fluide-cylinder- } 1}\right) \int D e_{6}}{I_{\text {Piston }}}-\right.\right.\right.\right. \\
& \left.\frac{A_{\text {Cylinder }}\left(I_{\text {fluide-pipe-1 }}+I_{\text {fluide-cylinder }-1}\right) D e_{6}}{I_{\text {Piston }}}\right)+ \\
& A_{\text {Cylinder }}\left(n_{2} \text { Se } e_{\text {Fluide-Source }}-\frac{A_{\text {Cylinder }}\left(R_{V_{2}}+R_{\text {fluide-pipe-2 }}+R_{\text {fluide-cylinder-2 }}\right) \int D e_{6}}{I_{\text {Piston }}}-\right.
\end{aligned}
$$


$\left.\left.\frac{A_{\text {Cylinder }}\left(I_{\text {fluide-pipe-2 }}+I_{\text {fluide-cylinder-2 }}\right) D e_{6}}{I_{\text {Piston }}}\right)-D e_{6}-\frac{R_{\text {Piston }} \int D e_{6}}{I_{\text {Piston }}}\right)-\frac{T f_{4} R_{\text {Handle }} \int D e_{6}}{I_{\text {Piston }}}-$

$\left.\left.\frac{T f_{4} I_{\text {Hande }} D e_{6}}{I_{\text {Piston }}}\right)-\frac{T f T f_{4} R_{\text {Rods }} \int}{I_{\text {Piston }}} \underline{D e_{6}}-D e_{7}\right)+\frac{T f T f_{2} T f_{4} R_{\text {Bearing }} \int D e_{6}}{I_{\text {Piston }}}+\frac{T f T f_{2}}{T f_{1}\left(I_{\text {Blade }}+I_{\text {Blade }}\right) D e_{6}}-$

Mse $\left._{\text {Eternal }}\right) \pm \omega_{1} \pm \omega_{2} \pm \omega_{3} \pm \omega_{4} \pm \omega_{5} \pm \omega_{6} \pm \omega_{7} \pm \omega_{8} \pm \omega_{9} \pm \omega_{10} \pm \omega_{11} \pm \omega_{12} \pm \omega_{13}(11)$

$$
\begin{aligned}
& \begin{array}{c}
\omega_{1}=\delta_{D e_{8}} \int D e_{8} \\
\omega_{2}=\delta_{D e_{6}} \frac{A_{\text {Cylinder }}^{2}\left(R_{V_{1}}+R_{\text {fluide-pipe-1 }}+R_{\text {fluide-cylinder-1 }-1}\right) \int D e_{6}}{T f T f_{2} T f_{4} I_{\text {Piston }}}
\end{array} \\
& \omega_{3}=\delta_{D e_{6}} \frac{A_{\text {Cylinder }}^{2}\left(I_{\text {fluide-pipe-1 }}+I_{\text {fluide-cylinder }-1}\right) D e_{6}}{T f T f_{2} T f_{4} I_{\text {Piston }}} \\
& \omega_{4}=\delta_{D e_{6}} \frac{A_{\text {Cylinder }}^{2}\left(R_{V_{2}}+R_{\text {fluide-pipe-2 }}+R_{\text {fluide-cylinder-2 }}\right) \int D e_{6}}{T f T f_{2} T f_{4} I_{\text {Piston }}} \\
& \omega_{5}=\delta_{D e_{6}} \frac{A_{\text {Cylinder }}^{2}\left(I_{\text {fluide-pipe-2 }}+I_{\text {fluide-cylinder-2 }}\right) D e_{6}}{T f T f_{2} T f_{4} I_{\text {Piston }}} \\
& \omega_{6}=\delta_{D e_{6}} \frac{D e_{6}}{T f T f_{2} T f_{4}} \\
& \omega_{7}=: \delta_{D e_{6}} \frac{R_{\text {Piston }} \int D e_{6}}{T f T f_{2} T f_{4} I_{\text {Piston }}} \\
& \omega_{8}=\delta_{D e_{6}} \frac{T f T f_{4} R_{\text {Rods }} \int D e_{6}}{T f_{2} I_{\text {Piston }}} \\
& \omega_{9}=\delta_{\text {De }_{6}} \frac{T f T f_{2} T f_{4} R_{\text {Bearing }} \int D e_{6}}{I_{\text {Piston }}} \\
& \omega_{10}=\delta_{D e_{6}} \frac{T f T f_{2} T f_{4}\left(I_{\text {Bearing }}+I_{\text {Blade }_{1}}+I_{\text {Blade }_{2}}\right) D e_{6}}{I_{\text {Piston }}} \\
& \omega_{11}=\delta_{D e_{6}} \frac{T f_{4} R_{\text {Handle }} \int D e_{6}}{T f T f_{2} I_{\text {Piston }}} \\
& \omega_{12}=\delta_{\text {De }_{6}} \frac{T f_{4} I_{\text {Handle }} D e_{6}}{T f T f_{2} I_{\text {Piston }}} \\
& \omega_{13}=\delta_{D e_{7}} \frac{D e_{7}}{T f_{2}}
\end{aligned}
$$

$A R R_{9}=$ Mse $_{\text {Eternal }}-D e_{9} \pm \omega$

$\omega=\delta_{D e_{9}} D e_{9}$

The resulted ARRs from these relations can be shown as:

$A R R_{i}: r_{i}+\sum \omega_{i}=0 \Rightarrow r_{i}=-\sum \omega_{i}$ 
This relationship express that, in the normal state operation of the system, the numerical values of the reminders, may not be zero, exactly, because of uncertainty in measurement, system parameters and modeling. Therefore, in the case that the reminders be in the allowed range. The fault detection alarm would not be triggered, despite that reminders be not zero.

Further to it, regard to statistics and probabilities, uncertainties can both recover and robust each other, so the allowed range for reminders must be shown as:

$a=\sum\left|\omega_{i}\right|$

The numerical value of $a$ shows the adapted threshold.

Using these equations ARR table can be established as below. If each of the elements, be present in each reminder's equation, 1 is written in its cell in the table, and otherwise 0 is written. In this table $\mathrm{M}_{\mathrm{b}}$ is observability index, and $\mathrm{I}_{\mathrm{b}}$ is the separability index. When some faults in the system is detected, the value 1 for the reminders that are out of range is set. If the result is like one of the rows of the table, it shows that its element has fault. It can be seen that the front and back muscles are not separated from each other, but it can be found from the direction of the desired movement.

Table 1. ARR table for the collective system

\begin{tabular}{|l|l|l|l|l|l|l|l|l|l|l|l|}
\hline & $\mathrm{r}_{1}$ & $\mathrm{r}_{2}$ & $\mathrm{r}_{3}$ & $\mathrm{r}_{4}$ & $\mathrm{r}_{5}$ & $\mathrm{r}_{6}$ & $\mathrm{r}_{7}$ & $\mathrm{r}_{8}$ & $\mathrm{r}_{9}$ & $\mathrm{M}_{\mathrm{b}}$ & $\mathrm{I}_{\mathrm{b}}$ \\
\hline $\mathrm{Df}_{1}$ & 1 & 1 & 1 & 0 & 1 & 0 & 0 & 0 & 0 & 1 & 1 \\
\hline $\mathrm{De}_{2}$ & 1 & 1 & 0 & 0 & 0 & 0 & 0 & 0 & 0 & 1 & 1 \\
\hline $\mathrm{Df}_{3}$ & 1 & 0 & 1 & 1 & 1 & 0 & 0 & 0 & 0 & 1 & 1 \\
\hline $\mathrm{De}_{4}$ & 0 & 0 & 1 & 1 & 0 & 0 & 0 & 0 & 0 & 1 & 1 \\
\hline $\mathrm{De}_{5}$ & 1 & 0 & 1 & 0 & 1 & 0 & 0 & 0 & 0 & 1 & 1 \\
\hline $\mathrm{De}_{6}$ & 0 & 0 & 0 & 0 & 0 & 1 & 1 & 1 & 0 & 1 & 1 \\
\hline $\mathrm{De}_{7}$ & 0 & 0 & 0 & 0 & 0 & 0 & 1 & 1 & 0 & 1 & 1 \\
\hline $\mathrm{De}_{8}$ & 0 & 0 & 0 & 0 & 0 & 0 & 0 & 1 & 0 & 1 & 1 \\
\hline $\mathrm{De}_{9}$ & 0 & 0 & 0 & 0 & 0 & 0 & 0 & 0 & 1 & 1 & 1 \\
\hline $\mathrm{MSe}_{5}$ & 1 & 0 & 0 & 0 & 1 & 0 & 0 & 0 & 0 & 1 & 0 \\
\hline $\mathrm{MSe}_{10}$ & 1 & 0 & 0 & 0 & 1 & 0 & 0 & 0 & 0 & 1 & 0 \\
\hline $\mathrm{MSe}_{17}$ & 0 & 0 & 1 & 0 & 0 & 0 & 0 & 0 & 0 & 1 & 0 \\
\hline $\mathrm{MSe}_{25}$ & 0 & 0 & 1 & 0 & 0 & 0 & 0 & 0 & 0 & 1 & 0 \\
\hline $\mathrm{MSe}_{90}$ & 0 & 0 & 0 & 0 & 0 & 1 & 1 & 1 & 1 & 1 & 1 \\
\hline $\mathrm{Se}_{99}$ & 0 & 0 & 0 & 0 & 0 & 1 & 1 & 1 & 0 & 1 & 1 \\
\hline
\end{tabular}

Now using this table it is tried to test the operation of the system. In this paper some approximate data for the system is used, and it is supposed that, in the middle of the operation the arm muscle of the pilot, breaks down, so the value of the source of effort that represent it $\left(\mathrm{MSe}_{5}\right)$, will be set to zero. The results of simulation are shown in figure 10. In this figure the reminder value is 
shown by blue line, and threshold values are shown by red lines. It can be seen that after break down, only 1 and 5 reminders fall out of range, also three later ones fall approximately, over the threshold. Therefore it means that one of the elements that show front and back muscles, has fault.

It should be noticed that because bond graph model of cyclic system is very similar to the collective system, its equation and ARR table will be very similar to it and could be established, but here it is neglected because of similarity and the system's long equations.
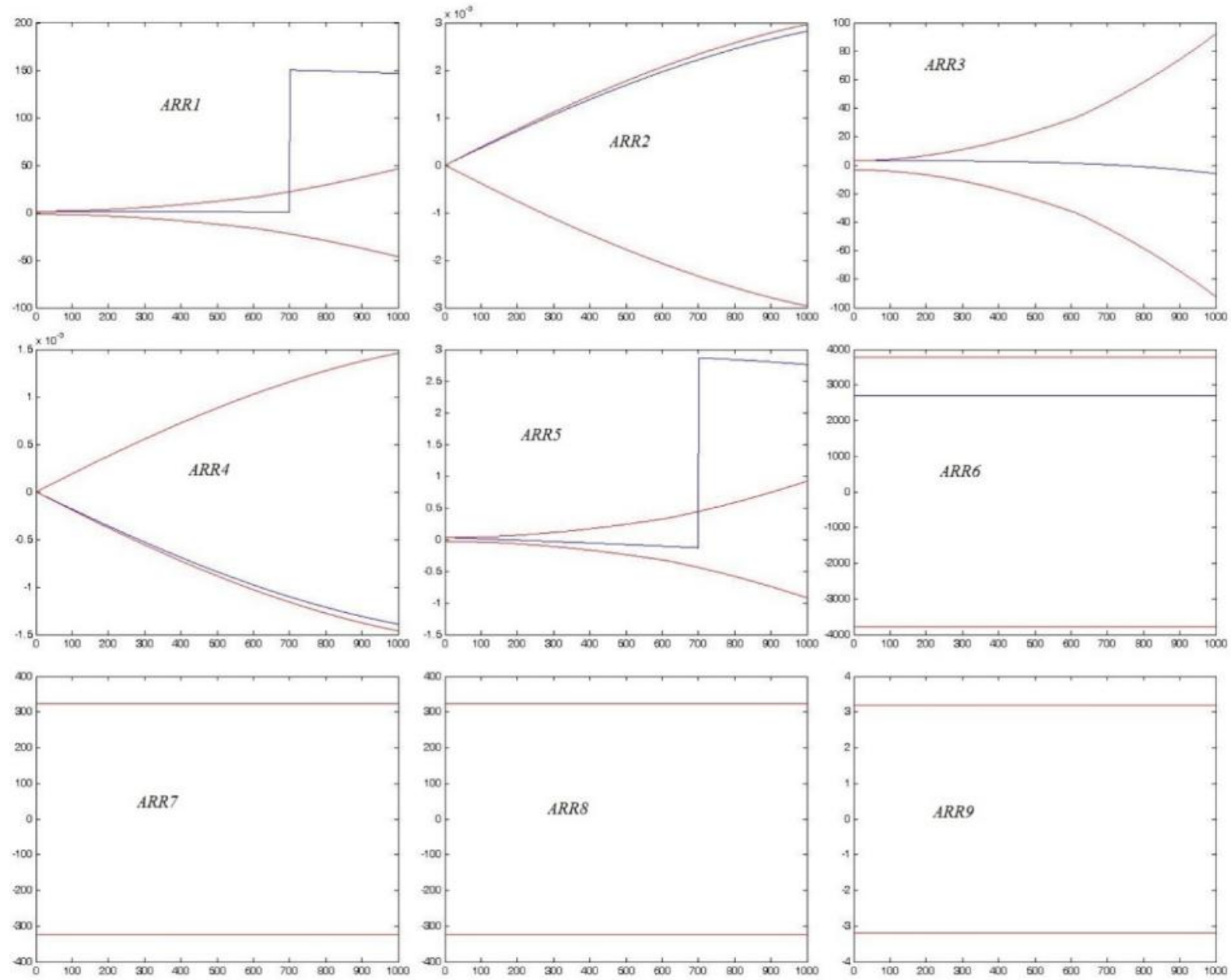

Fig.10. The results of ARR for simulation of the collective system

\section{CONCLUSION}

The object of this papers was developing a model for the integral system, containing the controlling systems of the helicopter and the pilot's body, and using it for creation of a fault 
detection system, that can detect the source of the fault. For this purpose the collective and cyclic controls of the helicopter was selected, that the pilot manipulate them by two handles. For modeling the system bond graph modelling method was selected because of its powerfulness in modeling dynamical and nonlinear systems. Also its ability to model multi-domain of energy systems, is a very prominent advantage that can be useful for this work. After designing the bond graph model of the system, sensors that control the systems added to the model, using FDI method for modeling sensors in bond graph modeling. Additionally, the presence of uncertainty in the systems was considered. For modeling a stable system that be robust against uncertainty, internal feedback loop (LFT) method was used. After that the overall model of the system that consist of fault detection and LFT model, was presented, and the equations for calculating the reminder values of the sensors was extracted and written. Using the produced equations ARR table for assessment of the system was stablished that could show the source of the fault. For validation of the system, a sample simulation for collective control system was simulated, that it was supposed in it that the arm of the pilot is broken down, and the results of simulation found out it. Therefore, the performed task in this paper can be useful in aviation industry to obtain the source of any fault that is occurred in a flying helicopter.

\section{REFERENCES}

Heinrich, H. W. 'Industrial accident prevention', McGraw-Hill, 1931.

Reason, J., 'The contribution of latent human failures to the breakdown of complex systems', Philosophical Transactions of the Royal Society (London), 1990.

Shappell \& Wiegmann,'The Human Factors Analysis and Classification System', HFACS. FAA. US Department of Transportation, 2000.

Senders, J. W. \& Moray, 'Human error. Cause, prediction, and reduction', Hillsdale, N.J.: Lawrence Erlbaum Associates, 1991.

Sanders, M. S. \& McCormick, E.J., 'Human Factors in Engineering and Design, $7^{\text {th }}$ Edition', McGraw-Hill Education, 1993.

Petersen, D., 'Human Error Reduction and Safety Management, $3^{\text {rd }}$ Edition', Van Nostrand Reinhold, New York, 1996.

Tustin, A., 'The Nature of the Operator's Response in Manual Control, and its Implications for Controller Design', journal of the IEE, 94, part IIA, 1947. 
McRuer, D. L., Weir, D.H., 'Theory of Manual Vehicluar Control', Ergonomics, 1969.

Kleinman, D. L., Baron, S., Levison, W.H., 'An Optimal Control Model of Human Response. Part I: Theory and Validation', Automatica, Pergamon press, 1970.

Hess,R.A., 'A Model-Based Theory for Analyzing Human Control Behavior', Advance in ManMachine Systems Research, 1985.

Cardullo, F, George. G., Latham, R., 'Force Cueing Technology Integration and Feedback Metrics to Improve DMO Simulator Effectiveness', Air Force Lboratory, Wright Patterson AFB, OH 45433, 2006.

Paynter, H.M., 'Analysis and Design of Engineering Systems', M.I.T. Press, Cambridge, Mass., 1961

Dauphin-Tanguy, G., Rahmani, A., \& Sueur, C., 'Bond graph aided design of controlled systems', Simulation Practice and Theory, 1999.

Feenstra, P.J., Mosterman, P.J., Biswas, G.,Breedveld, P.C., 'Bond graph modeling procedures for fault detection and isolation of complex flow processes', ICBGM'01, Simulation series, 2001. Tagina, M., Cassar, J. Ph., Dauphin-Tanguy, G., \& Staroswiecki, M., 'Monitoring of systems modelled by bond graph', International conference on bond graph modeling and simulation (ICBGM'95), Las Vegas, 1995.

Ould Bouamama, B., 'Bond graph approach as analysis tool in thermofluid model library conception', Journal of the Franklin Institute, 2003.

Glusman SI, Landis KH, Dabundo C., 'Handling qualities evaluation of the ADOCS primary flight control system', Proceedings of the American Helicopter Society 42nd annual forum, 1986. Majid Habibi, Mahdi Ghane, A. B. Novinzadeh, 'Modeling Integrative and Derivative Systems in Bond Graph Modeling and using it in Adaptive Control', Life Science Journal, 2013.

Amalendu M. Ranjit Karmakar, Arun K. Samantaray, 'Bond Graph in Modeling, Simulation and Fault Identification', I.K. International Publishing House Pvt. Ltd., 2006.

John C. Doyle, Joseph E. Wall, Gunter Stein, 'Performance and robustness analysis for structured uncertainty', 21st IEEE Conference on Decision and Control, 1982.

C. Sié Kam, G., Dauphin-Tanguy, 'Bond graph models of structured parameter uncertainties', Journal of the Franklin Institute, 2005.

W. Borutzky, G. Dauphin-Tanguy, 'Incremental Bond Graph Approach to the Derivation of State Equations for Robustness Study', Simulation Modelling Practice and Theory, 2004. 
W. Borutzky, G. Dauphin-Tanguy, C. Kam., 'Relations between two bond graph approaches to sensitivity analysis and study of robustness', Mathematical and Computer Modelling of Dynamical Systems, 2006.

How to cite this article:

Imani K, Novinzadeh A B, Toosi K N. Fault evaluation and adaptive threshold detection of helicopter pilot using bond graph method. J. Fundam. Appl. Sci., 2016, 9(1S), 344-365. 